\title{
Anthropogenic Disturbance and Edge Effects on Anuran Assemblages Inhabiting Cloud Forest Fragments in Colombia
}

\author{
Paola Johanna Isaacs Cubides ${ }^{1, *} \&$ José Nicolás Urbina Cardona ${ }^{2}$ \\ ${ }^{1}$ Laboratorio de Herpetología, Pontificia Universidad Javeriana, Bogotá, Colombia \\ ${ }^{2}$ Departamento de Ecología y Territorio, Pontificia Universidad Javeriana, Bogotá, Colombia
}

\begin{abstract}
Anurans have been affected by Andean forest fragmentation and loss, leading to impoverished ensembles along the pasture-forest gradients. We evaluated edge effects on tropical cloud forest anurans in three landscapes with a different degree of anthropogenic disturbance, and their relationships with eight environmental variables. On each landscape we set up 12 permanent transects (two per habitat type: streams in pastures, pastures, the outer limit of the pastures with the forest, the internal edge of the forest, the forest interior and streams inside the forest) and surveyed them using an equal effort. After an effort of 162 man-hours we recorded a total of 251 anurans of eight species. Richness was higher in the forest (seven species) than in pasture (four species). Most species of the ensemble (75\%) inhabited the forest habitats, whereas $50 \%$ of the anuran species inhabited the pasture. Slope and distance to streams influenced the distribution of all modeled Pristimantis species, although this genus exhibits direct development and doesn't require bodies of water for its reproduction. The canopy cover had a high explanatory power (through beta regressors) on the presence of anuran species in the microhabitat; whereas temperature and relative humidity did not, suggesting that temperature and relative humidity may be less important for frog distributions along pasture-forest gradients in cloud forest landscapes. The anthropogenic disturbance in the landscape, rather than the edge effects, affects the presence of two rare species (Pristimantis ptochus and Pristimantis kelephas) suggesting that these species display a high degree of sensitivity to the transformation of the cloud forest. Future cloud forest management research needs to incorporate anthropogenic disturbance effects, because it strongly interacts with edge and matrix effects, affecting the habitat quality and the persistence of species in the landscape.
\end{abstract}

Key words: Andean Forest, Anuran Diversity, Edge Effect, Environmental Variables, Habitat Fragmentation.

\section{Introduction}

Land use changes for agriculture, logging and urbanization have altered natural ecosystems, reducing them to small isolated patches of the original vegetation (Saunders et al. 1991). These remnants experience edge effects, which involve the flux of environmental and biological conditions from the anthropogenic matrix, affecting species composition and biotic interactions in native forests (Murcia 1995). The impact of the edge effects depends on the intensity or magnitude of the changes of certain response variables (e.g. temperature, relative humidity, vegetation cover, species richness) and the penetration distance of that factor from the edge to the interior (Ries et al. 2004). These changes increase the risk of species extinction due to stochastic variations and problems related with habitat quality loss,

\footnotetext{
*Send correspondence to: Paola Johanna Isaacs Cubides Laboratorio de Herpetología, Pontificia Universidad Javeriana Cra. 7 No. 43-82 - Edificio Carlos Ortíz $5^{\circ}$ piso

Javeriana, Bogotá, Colombia

E-mail: paola.isaacs@gmail.com
}

inbreeding depression and genetic diversity (Laurance et al. 2002). Historically habitat fragmentation studies have been focused on the effects of edges with a one-sided approach (Fonseca \& Joner 2007) treating the anthropogenic matrix as uniform and ecologically irrelevant (Jules \& Shahani 2003). Several authors reported an increase of anuran richness from the matrix to the forest interior, being higher in the ecotone, the intersection of the natural cover with the anthropogenic one (Toral et al. 2002; Urbina-Cardona \& Londoño 2003; Urbina-Cardona et al. 2006). Edge effects on amphibians may vary in strength among the land use types (Gascon et al. 1999; Toral et al. 2002; Pineda \& Halffter 2004; Santos-Barrera \& Urbina-Cardona 2011), and could be more influential for lowland (Urbina-Cardona et al. 2006) than highland species (Toral et al. 2002; Urbina-Cardona \& Perez-Torres 2002; Cortés et al. 2008).

Edge effects are key components to understanding how landscape structure influences in habitat quality (Ries et al. 2004). Urbina-Cardona et al. (2006) demonstrated that 
the edge effects on amphibian ensembles represent an indirect response to a cascade of effects, that involved environmental variables and suggested a strong relationship between environmental variables, such as vegetation cover, temperature and relative humidity, and other factors that modify habitat quality for amphibians such as food and shelter (Tocher et al. 2001).

Anurans are important subjects to study anthropogenic disturbance, because they play an important role in linking aquatic and terrestrial environments, influencing primary production and bioturbation in water bodies and actively participating in the transfer of energy and organic matter along food webs, acting as herbivores, predators, and prey. Some anuran species are susceptible to environmental changes due to their low dispersal abilities and ecophysiological characteristics such as skin permeability, inability to thermoregulate accurately and sensitivity to temperature and environmental humidity (Pough et al. 1998).

The matrix effects on amphibian dynamics depend on the regime of disturbance (sensu frequency and intensity) and structure of the vegetation and the heterogeneity along productive systems and forest gradients (Gascon et al. 1999; Ray et al. 2007; Cáceres-Andrade \& Urbina-Cardona 2009, Dixo \& Metzger 2010; Santos-Barrera \& Urbina-Cardona 2011). Specifically, in Andean regions the matrix effects are stronger than the edge effects on amphibian distribution and abundance (Tocher et al. 2001; Urbina-Cardona \& Perez-Torres 2002; Cortés et al. 2008), but their relationships with anthropogenic effects have never been evaluated. In this paper we evaluate changes in richness, abundance and composition of frog ensembles along habitat gradients (streams in pastures, pastures, the outer limit of the pasture with the forest, the internal edge of the forest, the forest interior and streams inside the forest) and their relationship with environmental variables in three landscapes with different anthropogenic disturbance in the Serrania de los Paraguas, Colombia.

\section{Methods}

\section{Study area}

We worked in three landscapes located in the Serrania de los Paraguas (SDLP), an isolated mountain system with an area of approximately 230,000-ha of cloud forest located in the foothills of the Cordillera Occidental of Colombia, between the Departments Chocó and Valle del Cauca ( $4^{\circ} 44.2^{\prime} \mathrm{N}$, $76^{\circ} 18.3^{\prime} \mathrm{W}$ to $4^{\circ} 44.5^{\prime} \mathrm{N}, 76^{\circ} 17.8^{\prime} \mathrm{W}$ ) (Serraniagua 2000).

The maximum rainfall is between 2,000 and 3,000 mm/year, with a bimodal rainfall regime, with two dry seasons (January - February and July - August) and two wet seasons (April - May and October - November). The average temperature oscillates between $10.2^{\circ} \mathrm{C}$ in the early morning and $30.7^{\circ} \mathrm{C}$ in the afternoon (Serraniagua 2000). It is composed of elevations between 300 to 2,500 m within in the Premontane Rain Forest life zones (Serraniagua 2000).

\section{Site selection}

The anurans were sampled in three landscapes with different anthropogenic disturbances: Vallecitos, Alto Bonito and La Cancana in the municipality of El Cairo, located in the highlands of the Serranía (Serraniagua 2000):

Vallecitos (V) was the landscape with the least anthropogenic disturbance. It is a continuous forest with an area of more than 60.000 ha located at an elevation of 2,200 m ( $4^{\circ} 47^{\prime} 16^{\prime \prime} \mathrm{N}$ and $76^{\circ} 13^{\prime} 55^{\prime \prime} \mathrm{W}$ ) with no human intervention because it is a private reserve for the water supply of the municipality. The forest edge is adjacent to pastures and stubbles.

Alto bonito $(\mathrm{AB})$ was the landscape with moderate anthropogenic disturbance, in the same continuous forest ( $>60.000 \mathrm{ha}$ ) of Vallecitos but on the other side of the mountain at an elevation of 2,200 m ( $4^{\circ} 49^{\prime} 19^{\prime \prime} \mathrm{N}$, $\left.76^{\circ} 12^{\prime} 40^{\prime \prime} \mathrm{W}\right)$. This landscape has an intermediate degree of human intervention with pasture and stubbles in an advanced regeneration stage.

La Cancana (C) was the landscape with the highest anthropogenic disturbance located at an elevation of 2,000 $\mathrm{m}$ $\left(4^{\circ} 46^{\prime} 48^{\prime \prime} \mathrm{N}, 76^{\circ} 13^{\prime} 18^{\prime \prime} \mathrm{W}\right)$ and it is a small isolated patch (30 ha) of remnant vegetation which is surrounded by pastures for cattle and coffee crops and bananas surround it (Serraniagua 2000).

In each landscape we sampled six habitats, three in the pasture: a) exterior; b) streams in pastures; and c) outer limit of the pastures with the forest; and three inside the forest: a) internal edge of the forest (from the physical edge of the forest up to $30 \mathrm{~m}$ inside it); b) forest interior (from 200 to $500 \mathrm{~m}$ inside the forest); and c) streams in forest. In each one of the habitats we established two permanent 50 long $3 \mathrm{~m}$ wide transects parallel to the forest edge, the placement of the transects were determined randomly. The distances between transects were set in accordance with the forest cover conditions and were never closer than $20 \mathrm{~m}$.

\section{Anuran surveys}

The surveys were conducted during three field sessions in September (dry season), October (transition between the dry and wet season) and November (wet season) 2003. Visual Encounter Surveys (Crump \& Scott 1994) were conducted along permanent replicated transects inside the landscape (Urbina-Cardona et al. 2006), sampled up to $2 \mathrm{~m}$ in height for 1.5 hours at night (7:00 to 10:00 PM). The total sampling effort was equivalent to $162 \mathrm{man} /$ hours along 36 transects, with the same effort in all transects. Of the recorded individuals, 52 (21\% of the observed individuals) were sacrificed and deposited in the Herpetological Collection of the Universidad del Valle, Cali, Colombia (Collect permits No. DG-1051). 


\section{Microhabitat measurements}

Eight environmental and structural variables (slope, elevation, distance from streams, canopy cover, shrub cover, herbaceous cover, temperature and relative humidity) were always measured by the same person. For each transect $(n=36)$ slope and elevation (meters above sea level) were measured using a clinometer and an altimeter, respectively, by averaging the values obtained from five randomly chosen places along the transect; the distance from streams was measured by geopositioning the nearest stream to the transect and using the Go To function on a GPS; the canopy cover (over $5 \mathrm{~m}$ of height), shrub cover (to $1 \mathrm{~m}$ of height) and herbaceous cover (up to $50 \mathrm{~cm}$ of height), was measured following Mattelucci \& Colma (1982) categories (continuous, 5: greater than 75\%; broken, 4: $75-50 \%$; scattered, $3: 50-25 \%$; rare, $2: 25-15 \%$; very rare, 1: 15-5\%; and almost absent, 0: less than 5\% (Mattelucci \& Colma 1982). For each individual $(n=251)$ we measured temperature and relative humidity in the microhabitat where the individual was first seen.

\section{Data analysis}

To compare the species richness among landscapes and habitats with an equal sampling effort, species accumulation curves were generated, using the sample-based rarefaction method of the Software EstimateS 8.0 (Colwell 2006). The function of expected richness (Sobs) is the accumulation function of species along transects per habitat $(n=36)$. Jack 1 and 2 richness estimators were used while assuming the heterogeneity of the samples (Magurran 2004), in mosaic landscapes and to measure the alpha diversity in forest (sum of the transects set on the edge, the interior and the stream habitats) and pasture (sum of the transects set on the outer edge, the streams and the exterior habitats). Additionally, we used the richness estimator of Bootstrap due to it is robustness for estimating the richness of ensembles with rare species (Magurran 2004). Based on the richness values predicted by the richness estimators (Jack 1 and 2, and bootstrap), we estimated the percentage of species that were represented on the inventory (sensu completeness Pineda \& Halffter 2004).

The species richness for each of the six habitats was estimated by three non-parametric richness estimators: Bootstrap, Chao 1 and Chao 2 using the Software EstimateS 8.0 (Colwell 2006). Chao 1 and 2 assume habitat homogeneity (Magurran 2004) and are therefore suitable for separately estimating the richness of anurans in each habitat.

We conducted a non parametric Mann-Whitney U test to compare the anuran abundance between two independent samples (e.g. pasture and forest). The abundance of anurans was compared between the landscapes and the six surveyed habitats using Kruskal-Wallis ANOVA in a rank test with the help of the software STATISTICA 6.0 (StatSoft 2001).
Using the Software PRIMER (Clarke and Gorley 2001), we generated Bray-Curtis similarity matrices for the amphibian data, using the normalized relative abundance of the species in each transect. Using these similarity matrices, we performed a non-parametric two-way analysis of similarity (ANOSIM subroutine) to test the hypotheses regarding the spatial differences in the amphibian composition. The ANOSIM procedure is a permutation-based test which can be applied to simple nested designs (e.g. habitats within landscapes) to detect differences between groups of multivariate samples (Clarke \& Gorley 2001).

To determine patterns in anuran species composition among habitats, we estimated similarity by a Principal Component Analysis, constructing a distance matrix between the samples in which anuran individuals were registered, based on standardized abundances $(\log 10)$ of the amphibian species using the Software MVSP 3.13 (Kovach 2004).

The normality and homogeneity of variance were assessed for the environmental and structural variables. We estimated the differences between temperature and relative humidity performing a chi-square test. The Pearson correlation coefficient was calculated to identify the relationship between the environmental variables and to identify groups of non-correlated variables inside the microhabitats of the anurans in transects on the pasture $(n=62)$ and the forest $(n=189)$.

We used forward stepwise multiple regression models in the software STATISTICA 6.0 (Statsoft 2001), to detect structural and environmental variables associated with the presence of the most common frogs (abundance $n=>5$ ). We previously excluded herbaceous cover, shrub cover and elevation because of their high colineality with other variables $(r=>0.7)$. The environmental variables that presented a non-significant $F$ test $(p<0.05)$ were eliminated from the model and for each model the normality of the residuals was assessed using a Shapiro-Wilk test (W).

\section{Results}

\section{Regional diversity}

Were recorded a total of 251 individuals of eight species of two genera in two families. The Strabomantidae family corresponded to $87 \%$ of the species (Table S1 in the Additional Supporting Information available at www.abecol. org.br), while Pristimantis was the most diverse genus (seven species). The Jack 1 and 2 estimators reflected a richness that was similar to the observed richness (SObs), representing $88.8 \%$ of the total estimated richness (Table S1).

\section{Alpha species diversity per landscape}

The species richness among the three landscapes ranged from eight species in $\mathrm{V}$ to four species in LC, being higher in the forest than in pasture. According the Jack 1 and 2 
estimators, the greatest diversity was found in $\mathrm{AB}(100 \%)$, followed by LC ( 66 to $80 \%$ ) and V (66 to $72 \%$ ). Jack 1 and 2 indicated that the sampling represented between $50 \%$ (in LC) and $100 \%$ of the richness in pastures (in AB and V) and between $54 \%$ (in V) and 100\% of the richness (in LC) in the forest (Table S1). The V landscape had exclusive rare species in the forest (Pristimantis ptochus and Pristimantis kelephas) and one species in the pasture (Dendropsophus columbianus; Table S1) that were not captured on the other landscapes.

\section{Patterns of anuran abundance}

About $34.6 \%$ of the total individual abundance was recorded in $\mathrm{V}$, followed by $32.6 \%$ in $\mathrm{AB}$ and $32.8 \%$ in LC. $35.4 \%$ of the total abundance in the forest was recorded in $\mathrm{V}$, followed by $32.8 \%$ and $31.7 \%$ in $\mathrm{AB}$ and $\mathrm{LC}$, respectively. Forty three percent of the total abundance in the pasture was recorded from $\mathrm{V}$, followed by $32.2 \%$ and $24.2 \%$ in $\mathrm{AB}$ and LC, respectively (Table S1).

\section{Alpha species diversity among habitats}

In general, anuran species richness was higher in the forest (seven species) than in the pasture (four species, Table S2 in the Additional Supporting Information available at www. abecol.org.br). The richest habitats were the edge, streams inside the forest and the forest interior (seven, six, and five species, respectively; Table S2). Chao 1, Chao 2 and Bootstrap richness estimators showed a greater number of species in forest streams, followed by the forest edge. It was therefore predicted that undetected species are likely to occur in the forest interior (one species), the forest edge (between one and two species) and in the forest streams (between one and four species); whereas in pasture it was indicated that $100 \%$ of the expected species in stream, edge and exterior habitats were detected.

\section{Patterns of amphibian abundance and richness}

There were no significant differences among the anuran abundance between the three landscapes $(\mathrm{H}=6.2 ; P=0.28)$. There was a statistical significant difference on anuran abundance between the forest and the pasture $(U=171.5$; $P=0.016)$. However, there were no significant differences in the abundance of anurans between the six surveyed habitats $(\mathrm{H}=8.02 ; P=0.15)$.

The habitat with the highest abundance of anurans was the forest $(75.3 \%)$, mainly inside the forest interior (31.1\%). In the pastures, the habitat with the greatest abundance was the exterior $(45.16 \%)$, followed by the edge of the forest (30.6\%).

From $62 \%$ of species that occurred in the interior of the forest, $P$. palmeri and P. erythropleura were the most abundant ( 78 and $14 \%$ respectively). At forest edge $87 \%$ of species occurred, with $P$. palmeri and $P$. erythropleura making up 50 and $34 \%$ of observations respectively. Of the four species recorded in pasture, only two species (25\% of the anurofauna) occurred with preferentiality in this habitat, D. columbianus and P. achatinus, with 100 and $92 \%$ of the total abundance in the pasture, respectively.

\section{Patterns of anuran composition}

ANOSIM determined that there was a difference between landscapes in respect to the amphibian composition $(P=0.007)$, and V (Vallecitos) was different. There were differences in amphibian composition between the land cover types pasture and cloud forest $(P=0.01)$. There was no difference in the amphibian composition between the six habitats (stream, edge, interior/exterior) nested within two land cover types (pasture or forest; $P=0.91$ ).

The principal component analysis determined that the first two ordination axes explained $92.1 \%$ of the variation in the composition of anurans and shows a clear pattern of differentiation in anuran composition among pasture (P-) and forest (F-) along the axis 2 (Figure 1). In pasture habitats, it is also possible to differentiate changes in anuran composition along the axis 2 among the exterior (P-Ex), the stream (P-S) and outer pasture edge (P-E) habitats (Figure 1).

\section{Microhabitat variables and their relation with anurans}

In the pasture, the average temperature was $15.8{ }^{\circ} \mathrm{C}$ (min: $13.5^{\circ} \mathrm{C}$; $\max : 18^{\circ} \mathrm{C}$; variance: 0.98 ) while in forest habitats the average temperature was $16.1^{\circ} \mathrm{C}$ ( $\mathrm{min}: 13.9^{\circ} \mathrm{C}$; max: $17.8^{\circ} \mathrm{C}$; variance: 1.22$)$; but there were no statistical differences between the temperature in pasture and forest $\left(\chi^{2}=1.27, \alpha=0.01, \mathrm{df}=27\right)$.

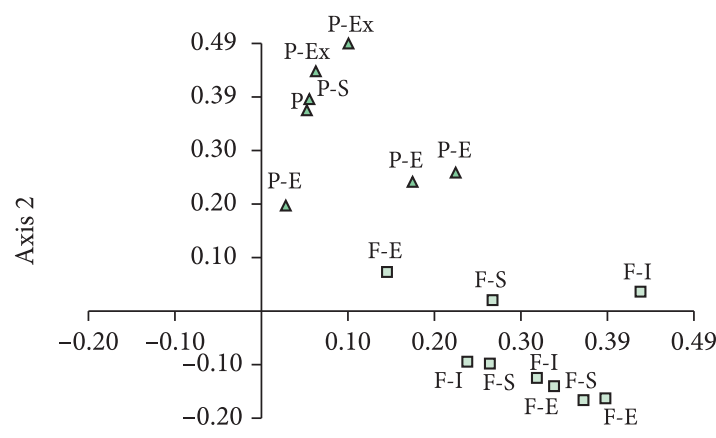

Axis 1

Figure 1. Principal Component Analysis based on the standardized abundances of the anuran species. Each triangle represents the coordinates of the species composition in each habitat. The first letter in the acronymus makes reference to Pasture ( $\mathrm{P}$ in triangle) or Forest ( $\mathrm{F}$ in square); the second letter (separated by a line) represents the habitats: stream (S), exterior (Ex), outer and internal edge (E) and interior (I). 
Relative humidity was not statistically different between the pasture and the forest $\left(\chi^{2}=4.65, \alpha=0.01, \mathrm{df}=27\right)$ showing an average of $84.31 \%$ for the pasture (range 65 to $94 \%$, variance 28.9 ) and $85.42 \%$ for forested areas (range 78.2 to $91 \%$, variance 11.9 ).

According to the Pearson correlation coefficients, we found 14 significantly direct relationships among the microhabitat variables of anurans in the forest and 18 in the pasture (Table 1). Of the relationships in the pasture habitats, the strongest were among elevation (height above sea level) and herbaceous (70\%) and shrub cover (-73\%); and between herbaceous and shrub cover (-94\%). In the forest habitats there were strong relationships between canopy cover and shrub cover (-87\%) and herbaceous cover $(-73 \%)$; and among the herbaceous cover in relation with the slope (-75\%).

The variable that positively determined the presence of P. achatinus in the microhabitat was the slope, whereas the variables that determined the presence negatively were the temperature, the canopy cover and distance from streams (Table 2); the variables that positively determined the presence of $P$. erythropleura in the microhabitats evaluated were the temperature and relative humidity, whereas the slope and distance from streams affected it negatively (Table 2); The variable that positively determined the presence of P. kelephas in the microhabitats was distance from streams and slope, and negatively it was the temperature (Table 2); The variables that positively determined the presence of P. palmeri in the microhabitat was the canopy cover and the distance from streams, and negatively the relative humidity and slope (Table 2); The variable that positively determined the presence of $P$. sp in the microhabitat was the relative humidity, the canopy cover and the slope, and negatively the distance from streams (Table 2).

\section{Discussion}

The Serrania de los Paraguas (SDLP) has been subjected to anthropogenic intervention that possibly affects the composition of anurans leading to a decline in population and species richness. It is important to consider that Lynch $(1998,1999)$ and more recently Universidad del Valle students, have surveyed the zone since 1981 and until 2006 extensively, and reported 38 anuran species known in SDLP for the elevation we sampled on (2000-20200 m), but excluded anthropogenic matrices inside the survey. Here we report only eight species; although Jack 1 and 2 richness estimators determined that the present study reported eight out of the nine expected species $(88.8 \%$ of the total estimated richness). We reported an anuran ensemble inhabiting pasture-forest gradients with a survey effort equivalent to $162 \mathrm{man} /$ hours (three months in one year) along three landscapes; so it's difficult to make robust inferences on local extinctions of species, due to the fragmentation, based on the historical inventory, and separately interpret those possible extinction cascades by the effects of infections with Batrachochytrium dendrobatidis fungus on amphibian skin in the region (Velásquez-E et al. 2008) as well as the affect of climate change on high mountain anurans (Urbina-Cardona 2011).

As the area of remaining forests is diminished, there is a loss of habitat quality and the proportion of microhabitats available for amphibian reproduction, foraging and

Table 1. Pearson correlation coefficients among eight environmental variables measured at the Serrania de los Paraguas in the Cordillera Occidental of Colombia. The upper right values from the bold diagonal make reference to microenvironment correlations in the pasture and the lower left values from the bold diagonal make reference to microenvironment correlations in the forest*

\begin{tabular}{lccccccccc}
\hline & Temperature & $\begin{array}{c}\text { Relative } \\
\text { humidity }\end{array}$ & $\begin{array}{c}\text { Herbaceous } \\
\text { cover }\end{array}$ & $\begin{array}{c}\text { Shrub } \\
\text { cover }\end{array}$ & $\begin{array}{c}\text { Canopy } \\
\text { cover }\end{array}$ & $\begin{array}{c}\text { Elevation } \\
\text { Slope }\end{array}$ & $\begin{array}{c}\text { Dist. from } \\
\text { streams }\end{array}$ \\
\hline Temperature & $\mathbf{1}$ & 0.09 & $-0.41^{\mathrm{c}}$ & $0.4^{\mathrm{b}}$ & -0.18 & $-0.56^{\mathrm{c}}$ & 0 & $-0.38^{\mathrm{c}}$ \\
Relative humidity & -0.12 & $\mathbf{1}$ & 0.01 & -0.006 & $-0.25^{\mathrm{a}}$ & -0.22 & 0.13 & 0.06 \\
Herbaceous cover & -0.06 & -0.02 & $\mathbf{1}$ & $-0.94^{\mathrm{c}}$ & -0.09 & $-0.7^{\mathrm{c}}$ & $-0.45^{\mathrm{c}}$ & $-0.61^{\mathrm{c}}$ \\
Shrub cover & -0.006 & 0.13 & $0.44^{\mathrm{c}}$ & $\mathbf{1}$ & $0.3 \mathrm{~b}$ & $-0.73^{\mathrm{c}}$ & $0.45^{\mathrm{c}}$ & $0.38^{\mathrm{c}}$ \\
Canopy cover & -0.1 & -0.12 & $-0.73^{\mathrm{c}}$ & $-0.87^{\mathrm{c}}$ & $\mathbf{1}$ & $0.25^{\mathrm{a}}$ & $-0.41^{\mathrm{c}}$ & $-0.48^{\mathrm{c}}$ \\
Elevation & $0.22^{\mathrm{b}}$ & 0.12 & $-0.25^{\mathrm{a}}$ & 0.1 & -0.4 & $\mathbf{1}$ & $-0.7^{\mathrm{c}}$ & $-0.53^{\mathrm{c}}$ \\
Slope & 0.01 & $0.15^{\mathrm{a}}$ & $-0.75^{\mathrm{c}}$ & 0.07 & $0.32^{\mathrm{c}}$ & $0.29^{\mathrm{c}}$ & $\mathbf{1}$ & $0.34^{\mathrm{b}}$ \\
Distance from streams & $-0.17^{\mathrm{a}}$ & $-0.18^{\mathrm{b}}$ & $-0.14^{\mathrm{a}}$ & -0.01 & 0.01 & $0.24^{\mathrm{c}}$ & $-0.16^{\mathrm{a}}$ & $\mathbf{1}$ \\
\hline${ }^{\mathrm{b}}$ & & & & & & & & &
\end{tabular}

${ }^{\star} P$-values ${ }^{\mathrm{a}}<0.05,{ }^{\mathrm{b}}<0.01,{ }^{\mathrm{c}}<0.001$.

Table 2. Regression models for anuran species found in the Serrania de los Paraguas in the Cordillera Occidental of Colombia*.

\begin{tabular}{|c|c|c|c|c|}
\hline Species & Regression model & Multiple R (\%) & F test & $P$ \\
\hline Pristimantis achatinus & $y=0.97-0.69^{\star} c+0.08^{\star} d-0.07^{\star} a-0.05^{\star} e$ & 71.1 & 62.8 & $<0.001$ \\
\hline Pristimantis erythropleura & $y=-1.85+0.17^{\star} b-0.16^{\star} d+0.12^{\star} a-0.08^{\star} e$ & 29.1 & 5.71 & $<0.001$ \\
\hline Pristimantis kelephas & $y=0.087+0.23^{\star} e-0.09^{\star} a+0.07^{\star} d$ & 25.1 & 5.55 & $<0.001$ \\
\hline Pristimantis palmeri & $y=2.55+0.47^{*} c-0.24^{*} d-0.2^{\star} b+0.09^{*} e$ & 63 & 40.5 & $<0.001$ \\
\hline Pristimantis sp. & $y=-0.53+0.17^{\star} c+0.12^{\star} b-0.12^{\star} e+0.07^{\star} d$ & 26.2 & 3.6 & 0.0034 \\
\hline
\end{tabular}

*a. Temperature; b. relative humidity; c. canopy cover; d. slope; e. distance from streams. 
oviposition (Tocher et al. 2001; Urbina-Cardona et al. 2006). Although, one undeniable fact of the region is that the fragmentation and the loss of cloud forests is increasing because of the change of the land use towards crops and cattle. The two species that were exclusively present in the forest (Pristimantis ptochus and Pristimantis kelephas), the landscape with the least anthropogenic disturbance, which were apparently not directly affected by the edge effects, could disappear if fragmentation, loss and degradation of the habitat continues in the region.

Anthropogenic disturbances generate changes in the anuran composition, diversity and abundance, although the influence of those variables changes between seasons and gradients of natural-anthropogenic habitats (UrbinaCardona et al. 2006; Cáceres-Andrade \& Urbina-Cardona 2009). Although the anuran richness tends to increase towards the ecotone, it seems that forest edge negatively influences the abundance of the anurans in both directions of the gradient. It has been reported that the forest edge is the preferred habitat for the amphibians moving along the ecotone, for the means of reproduction or those that are just passing through (Gascon et al. 1999; Santos-Barrera \& Urbina-Cardona 2011). This is in contrast with other studies, where anurans responded negatively to the anthropogenic matrix but didn't change their abundances between the Andean forest edge and the interior (Toral et al. 2002; Urbina-Cardona \& Perez-Torres 2002) suggesting a high plasticity of the anurans and an individual response of the species to edge effects.

Relative humidity and temperature didn't show a strong explanatory power in the regression models, reinforcing the suggestion of Toral et al. (2002), that the edge effect in tropical montane ecosystems can be amortized by the mist. However, during the day the temperature and relative humidity fluctuations are highly variable, a factor that could affect the presence of species throughout the vegetation cover. The canopy regulates the micro-climate and the structural heterogeneity of vegetation, because it provides greater microhabitat diversity and resources, and produces components that reduce resource competition and allows coexistence (Urbina-Cardona \& Perez-Torres 2002).

The anurans depend on humidity levels and proximity to water sources for their survival and reproduction (Pough et al. 1998); only D. columbianus had a different reproductive modus by laying tadpoles in the water where vocalizing males were abundant, in the streams within the pastures; while the genera Pristimantis lays eggs in the leaf litter, independently of bodies of water due to their direct reproductive development mode. In the present study all the presence of the Pristimantis species was related with the distance from streams. However, although there is no direct dependence on water by the Pristimantis species, it seems that there must be certain humidity levels to guarantee their survival, given that Pristimantis anurans were not found in the exterior of pasture (except for P. achatinus, Pineda \& Halffter 2004).
According to Cortés et al. (2008), the genus Pristimantis is negatively affected by fragmentation, however in this study we found that $P$. achatinus used the stream habitats in forests as well as in pastures. It has been previously shown that this species has a resilient response to anthropogenic disturbance in the tropical rainforest (Urbina-Cardona \& Londoño 2003).

Andean streams cannot be regarded as a refuge for the anurofauna of cloud forest in open areas, or as important connectivity elements in tropical montane habitats, contrasting with the suggestions of De Lima \& Gascon (1999) for lowlands. Although forest streams did not present a high richness and abundance, or exclusive species, this habitat has the highest number of shared species between the edge and the interior of the forest, indicating that it can amortize edge effects increasing the habitat quality inside the forest remnants and the structural heterogeneity along the habitats gradient. In accordance to Pineda \& Halffter (2004) the cloud forest fragments are not enough to support the whole anurofauna in the region; anthropogenic matrices are important to for some species, such as Dendropsophus columbianus, generating a diverse system of habitats crucial for the species conservation in this seminatural landscapes.

The evident worldwide decline in the anuran populations is alarming; the principal causes could be habitat loss, emerging diseases, contaminants, overexploitation, invasive species and climate change. Due to the fact that the Colombian cloud forests have been extensively transformed into pastures, for crops and internally degraded by selective logging, it is important to continue with studies in the area to determine the direct and indirect human impacts on the anurans and to determine if there is a response to the effects of habitat fragmentation and loss, normal population fluctuations, the effect of an emergent disease (Lynch \& Grant 1998; Velásquez-E et al. 2008) other synergistic effects such as invasive species or climate change (Urbina-Cardona 2011). Nonetheless, future studies must consider natural history traits of the species (e.g. reproductive modes, size, habitat affinities and dispersal) to better understand the functional responses along anthropogenic matrix-forest gradients (Pineda \& Halffter 2004; Dixo \& Metzger 2010).

\section{Acknowledgements}

R. Loyola and three anonymous reviewers provided helpful suggestions that improved this manuscript. We want to thank Nick Bayly and Marek Grote assistance in editing the English version of this document. To LilianaTorres and Serraniagua Corporation for the field support. Andres Acosta, Fernando Castro, Wilmar Bolivar and Taran Grant assisted in the determination and revision of the taxonomic status of the amphibians. To the Corporación Autónoma Regional (CVC) for the collect permits. To José David Gómez for their comments on an earlier version of this manuscript. To Edwart Llanos, Andres Restrepo and the people of El Cairo for the hospitality, kindness and giving us strength and reasons to continue with these studies. 


\section{References}

Cáceres-Andrade S \& Urbina-Cardona JN, 2009. Ensamblajes de anuros de sistemas productivos y bosques en el piedemonte llanero, Departamento del Meta, Colombia. Caldasia, 31:175-194.

Clarke KR \& Gorley RN, 2001. PRIMER User Manual: Plymouth Routines in Multivariate Ecological Research. Plymouth: Plymouth Marine Laboratory.

Colwell RK. 2006. EstimateS 8.0: Statistical estimation of species richness and shared species from samples. User's Guide and Application. Department of Ecology and Evolutionary Biology, University of Connecticut, Storrs. Available from: <http://purl.oclc.org/estimates $>$.

Cortés A et al., 2008. Edge effects on richness, abundance and diversity of frogs in Andean cloud forest fragments. South American Journal of Herpetology, 3:213-22. http:// dx.doi.org/10.2994/1808-9798-3.3.213

Crump ML \& Scott NJ, 1994. Visual Encounter Surveys. In: Heyer W. et al., editors. Measuring and Monitoring Biological Diversity: Standard Methods for Amphibians. Washington: Smithsonian Institution Press.

De Lima MG \& Gascon C, 1999. The conservation value of linear forest remnants in central Amazonia. Biological Conservation, 91:241-247.

Dixo M \& Metzger JP, 2010. The matrix-tolerance hypothesis: an empirical test with frogs in the Atlantic Forest. Biodiversity and Conservation, 19:3059-3071. http:// dx.doi.org/10.1007/s10531-010-9878-x

Fonseca C \& Joner F, 2007. Two-sided edge effect studies and the restoration of endangered ecosystems. Restoration Ecology, 15:613-619. http://dx.doi. org/10.1111/j.1526-100X.2007.00273.x

Gascon C et al., 1999. Matrix habitat and species persistence in tropical forest remnants. Biological Conservation, 91:223229. http://dx.doi.org/10.1016/S0006-3207(99)00080-4

Jules ES \& Shahani P, 2003. A broader ecological context to habitat fragmentation: Why matrix habitat is more important than we thought. Journal of Vegetation Science, 14:459-464. http://dx.doi.org/10.1111/j.1654-1103.2003. tb02172.x

Kovach Computing Services. 2004. MVSP - MultiVariate Statistical Package. v. 3.13I. Available from: <www. kovcomp.com>.

Laurance WF et al., 2002. Ecosystem decay of Amazonian forest fragments: a 22-year investigation. Conservation Biology, 16:605-618. http://dx.doi. org/10.1046/j.1523-1739.2002.01025.x

Lynch JD, 1998. New species of Eleutherodactylus from the cordillera occidental of western Colombia with a synopsis of the distributions of species in western Colombia. Revista de la Academia Colombiana de Ciencias Exactas, Físicas y Naturales, 22:117-148.

Lynch JD, 1999. Lista anotada y clave para las ranas (género Eleutherodactylus) chocoanas del Valle del Cauca, y apuntes sobre las especies de la cordillera occidental adyacente. Caldasia, 21:184-202.

Lynch JD \& Grant T, 1998. Dying frogs of western Colombia: catastrophe or trivial observation. Revista de la Academia Colombiana de Ciencias Exactas, Físicas y Naturales, 22:149-152.

Magurran AE, 2004. Measuring Biological Diversity. Oxford: Blackwell Publishing.

Mattelucci S \& Colma A, 1982. Metodología para el estudio de la vegetación. Washington: Secretaría General de la Organización de los Estados Américanos.

Murcia C, 1995. Edge effects in fragmented forest implications for conservation. Trends in Ecology and Evolution, 10:5862. http://dx.doi.org/10.1016/S0169-5347(00)88977-6

Pineda E \& Halffter G, 2004. Species diversity and habitat fragmentation: frogs in a tropical montane landscape in México. Biological Conservation, 117:499-508. http:// dx.doi.org/10.1016/j.biocon.2003.08.009

Pough H et al., 1998. Herpetology. New Jersey: Ed. Prentice Hall.

Ray NL, Lehmann A \& Joly P, 2007. Modeling spatial distribution of amphibian populations: a GIS approach based on habitat matrix permeability. Biodiversity and Conservation, 11:2143-2165. http://dx.doi. org/10.1023/A:1021390527698

Ries L et al., 2004. Ecological responses to habitat edges: mechanisms, models, and variability explained. Annual Review of Ecology, Evolution, and Systematics, 35:491-522. http://dx.doi.org/10.1146/annurev. ecolsys.35.112202.130148

Santos-Barrera G \& Urbina-Cardona JN, 2011. The role of the matrix-edge dynamics of amphibian conservation in tropical montane fragmented landscapes. Revista Mexicana de Biodiversidad, 82:19-27.

Saunders D, Hobbs R \& Margules C, 1991. Biological consequences of ecosystem fragmentation: A review. Conservation Biology, 5:18-32. http://dx.doi. org/10.1111/j.1523-1739.1991.tb00384.x

Serraniagua, 2000. Plan de Ordenamiento Territorial (POT) del municipio de El Cairo -Valle del Cauca. Colombia: Gobernación del Valle.

StatSoft, 2001. STATISTICA: Data Analysis Software System. Version 6.0. Oklahoma: StatSoft.

Tocher M, Gascon C \& Meyer J, 2001. Community composition and breeding success of Amazonian frogs in continuous forest and matrix habitat aquatic sites. In: Bierregaard Junior R et al., editores. Lessons from Amazonia: The Ecology and Conservation of a Fragmented Forest. Yale University Press. U.S.A. p. 235-247.

Toral E, Feinsinger P \& Crump ML, 2002. Frogs and cloudforest edge in Ecuador. Conservation Biology, 16:735-744. http://dx.doi.org/10.1046/j.1523-1739.2002.00250.x

Urbina-Cardona JN, 2011. Gradientes andinos en la diversidad y patrones de endemismo en anfibios y reptiles 
de Colombia: Posibles respuestas al cambio climático. Revista de la Facultad de Ciencias Básicas -Universidad Militar Nueva Granada, 7:in press

Urbina-Cardona JN \& Londoño MC, 2003. Distribución de la comunidad de herpetofauna asociada a cuatro áreas con diferente grado de perturbación en la Isla Gorgona, Pacífico colombiano. Revista de la Academia Colombiana de Ciencias Exactas, Físicas y Naturales, 27:105-113.

Urbina-Cardona JN, Olivares-Pérez M \& Reynoso VH, 2006. Herpetofauna diversity and microenvironment correlates across the pasture-edge-interior gradient in tropical rainforest fragments in the region of Los Tuxtlas, Veracruz. Biological Conservation, 132:61-75. http://dx.doi.org/10.1016/j.biocon.2006.03.014

Urbina-Cardona JN \& Pérez-Torres J, 2002. Dinámica y preferencias de microhábitat en dos especies del genero Eleutherodactylus (Anura: Leptodactylidae) de Bosque Andino. In: Memorias del Congreso Mundial de Páramos; 2002; Bogotá, Colombia. Bogotá: MInisterio del Medio Ambiente. p. 278-288. Tomo I.

Velásquez-E BE et al., 2008. Infección por el hongo quitridio Batrachochytrium dendrobatidis en anuros de la Cordillera Occidental de Colombia. Herpetotropicos, 4:65-70.

Received: January 2011

First Decision: April 2011

Accepted: May 2011 